\title{
Statistical Approaches to the Evaluation of the Demand and Supply at the Labour Market Based on Panel Data
}

\author{
Tatyana V. Sarycheva ${ }^{1} \&$ Mikhail N. Shvetsov ${ }^{1}$ \\ ${ }^{1}$ Mari State University, Yoshkar-Ola, Russia \\ Correspondence: Tatyana V. Sarycheva, Mari State University, Lenin Square 1, Yoshkar-Ola, 424000, Russia.
}

Received: February 21, 2015

Accepted: March 15, 2015

Online Published: April 29, 2015

doi:10.5539/res.v7n8p356

URL: http://dx.doi.org/10.5539/res.v7n8p356

\begin{abstract}
The labour market as any trade market is based on demand and supply. In this case, the demand takes the form of the need to occupy free job positions and to perform work, and the supply represents the availability of unemployed workforce or a desire to change job. Demand and supply are implemented in competition, on the one hand, between workers for occupying a particular job or performing work, and, on the other hand, between employers for engagement of the necessary workforce in terms of quantity and quality. A fair solution of this competitiveness implies observance of a number of conditions. First of all, it is the mobility of workforce and rational distribution of production forces. In modern economy there is a situation, when the labour supply is reducing primarily due to the influence of demographic trends. For certain sectors of economy, the labour shortage becomes especially acute, since it has not only quantitative but also qualitative and structural nature. The decision of structural problems of employment and labour market will contribute to alleviation of labour shortage.

In the present article the main factors which form the demand and supply at the labour market at both national and regional level are identified and analyzed. Absolute and relative values of structural unbalanced employment are evaluated in the Mari El Republic by economic activities. The authors have formulated the methodology of the demand and supply evaluation, based on regressive models using panel data, which allowed not only to identify the influence of explanatory variables on the number of employed population, but also to take into account time effects. We have presented forecasting and analytical tools, have described the main preconditions and principles of models' construction, have carried out approbation of the suggested methods and models and have given the results of calculation of the dynamics and structure of the main indicators in the sphere of employment and the labour market of the region. Analysis and forecasting of socio-economic processes and identifying their relations is an essential condition for dynamic development of the national economy and for the growth of welfare of the citizens. The definite advantage of the suggested approach is its universality and applicability to the evaluation of the dynamics and structure of various socio-economic indicators and their structures.
\end{abstract}

Keywords: employment, labour market, demand and supply, panel data, regression model

\section{Introduction}

The labour market as a system of ordered relationships between the demand for workforce and its supply is an essential part of economic space of the country and naturally depends on the dynamics of its development and the changes in its structure. Therefore the influence of various factors should be taken into account in the analysis of dynamics of employment and the labour market.

The future of the Russian labour market is largely determined by the state of the local markets. It is impossible to achieve detente at the Russian labour market without addressing the emerging problems at the regional level. On the other hand, in spite of the commonality of the problems in the sphere of employment, there are certain regional peculiarities, and to take them into account it is necessary to conduct such a study of the processes at the regional labour market. In turn, the dynamics of the regional labour market is determined by both changes in regional factors and processes at the national labour market. Besides, the regional labour market should be considered by analogy with the national market in the light of existence of smaller local markets of labour, for each of which the problem of matching the demand and supply of workforce should be solved. 
The demand for labour is influenced by basic macroeconomic factors and trends. The number of employed quantitatively reflects the aggregate demand for labour; its structure by economic activities is primarily determined by the volumes of production and investment to fixed capital, because these create new jobs. The supply of labour reflects the willingness of workers to sell their labour for the existing market reward. The value of the aggregated supply is directly influenced by the policy in the sphere of income and wages and by the quality of labour potential. Along with the demand for labour, the supply of labour is subject to regulation under the state policy in the sphere of income and wages, employment policy and actions at the labour market in order to coordinate them.

Mismatch of the demand and supply leads to unemployment or labour shortage. These phenomena coexist at the modern Russian labour market. At present, the Russian economy faces the situation, when the supply of domestic workforce is reducing, primarily due to demographic trends. For certain economic sectors and regions (including the labour market of the Mari El Republic) the shortage of workforce will be especially acute, as it has not only quantitative but also qualitative and structural nature.

Full busyness of resources is the foundation for the achievement of the production maximum if other things being equal. If resources are not fully busy, this leads to underproduction. If we consider this statement in terms of such resource as labour, we can made a conclusion that the maximum possible volumes of production of goods and services in this country can be achieved only with the full employment of economically active population. But at the same time, as the labour market belongs to resource markets, the busyness of this resource is a very important income producing factor.

\section{Methods \& Materials}

Panel data is represented by tracked over time spatial macroeconomic samplings, i.e. they consist of observations of the same economic units, which are carried out in successive time periods. Panel data has three dimensions: features - objects - time. Use of them gives a number of significant advantages while evaluating the parameters of regressions:

- Use of panel data allows to take into account individual characteristics of objects;

- The number of observations increases and consequently the number of the degrees of freedom grows due to the decrease in dependence between explanatory variables and the model improves;

- The problem of incorrect specification of model is eliminating due to the non-inclusion of some variables in analysis.

The original panel data model looks as follows:

$$
y_{i t}=\beta_{0}+\sum_{i=1}^{m} \beta_{i} x_{i t}+u_{i t}
$$

There exist various approaches to the analysis of panel data. There are four types of models:

Pooled model. Parameters of this model $(m+1)$ are estimated using the OLS method for all $n_{T}$ observations and the specifics of the panel data is not taken into account. It is considered that the dependent variable linearly depends on all variables at the same time.

Unrelated models. Using the OLS method, the parameters $N$ of individual equations with $T$ observations in each equation are estimated. The method does not imply any relationships between the individual units of observation

Fixed effect model-FE-model. In this case, the original model of the regression panel analysis will look as follows:

$$
y_{i t}=a_{i}+\beta^{\prime} x_{i t}+\varepsilon_{i t}, i=1,2, \ldots, N, t=1,2, \ldots, T .
$$

Individual effect $a_{i}$ is constant during all periods $t=1, \ldots T$ for each object $i=1, . ., N$. The vector of regressors does not include a unit vector. If we assume that individual effects $a_{i}$ are equal for all objects, we will obtain an ordinary regression model. By applying the OLS method, we find effective estimates $a$ and $\beta$. If we consider $a_{i}$ as a constant value, reflecting the level, which is specific for each object, we will obtain a fixed effect model. The point of $a_{i}$ is to reflect the influence of missing or unobserved variables which characterize individual features of the considered objects, which do not change with time. The differences between the objects can be eliminated y introducing various free coefficients $a_{i}$. Thus, $a_{i}, i=1,2, \ldots, N$ are unknown parameters which we should estimate.

Let $y_{i}$ be a vector of the values of independent variables for $i$ object of dimension $T ; x_{i}$ be a matrix of the 
values of regressors for $i$ object of dimension $T \times K$, and let $\varepsilon_{i}$ be a vector of errors of dimension $T \times 1$. Then we can present (2) as follows:

$$
y_{i t}=i a_{i}+X_{i t} \beta+\varepsilon_{i t}, \quad i=1,2, \ldots, N,
$$

where $i$ is a vector which consists of units of dimension $T$.

Combining the equations into a single system, we obtain:

$$
\left[\begin{array}{c}
y_{1} \\
y_{2} \\
\ldots \\
y_{N}
\end{array}\right]=\left[\begin{array}{cccc}
i & 0 & \ldots & 0 \\
0 & i & \ldots & 0 \\
\ldots & \ldots & \ldots & \ldots \\
0 & 0 & \ldots & i
\end{array}\right] *\left[\begin{array}{c}
a_{1} \\
a_{2} \\
\ldots \\
a_{N}
\end{array}\right]+\left[\begin{array}{c}
X_{1} \\
X_{2} \\
\ldots \\
X_{N}
\end{array}\right] * \beta+\left[\begin{array}{c}
\varepsilon_{1} \\
\varepsilon_{2} \\
\ldots \\
\varepsilon_{N}
\end{array}\right], \text { ¿ } 2 \mathrm{i}=\left[\begin{array}{c}
1 \\
1 \\
\ldots \\
1
\end{array}\right]
$$

Having denoted the vector of constants, which correspond to the determined individual effects, as $A=\left[a_{1} \ldots a_{N}\right]$ and the matrix of dummy variables, which stands before the vector $A$, as $Z$, we will obtain the following matrix expression:

$$
y=Z A+X \beta+\varepsilon
$$

This model does not contain the common constant (the same for all observations), the matrix (XZ) will have full rank, and the model can be estimated using the OLS method. Such models are called least squares dummy variable (LSDV) regression models. A fixed effect model is based on the assumption that the differences between the object can be considered as time-independent values. If it is necessary to extend the model for the objects which are not included in the sample, it should be taken into account that the values of individual effects for these objects are unknown and the model is not applicable.

Random effect model (RE-model) is based on the assumption that $a_{i}$ is a certain random value which is uncorrelated with the regressors, included in the model. The model, which includes $K$ regressors, can be written as follows:

$$
y_{i t}=a+\beta^{\prime} x_{i t}+u_{i}+\varepsilon_{i t}
$$

The component $u_{i}$ is a random deviation (random error) which corresponds to $i$ object and to a time-independent value. This value may correspond, for example, to the combined effect of factors, specific to a particular area, family, individual, etc., which is not included in the number of regressors.

The quality of a panel data model can be measured using the coefficients of determination $\left(R^{2}\right) . R^{2}$ refers to the squares of the sample correlation coefficients between the observed and estimated values of the explanatory variable, which are specified in the appropriate form. In panel data analysis, three variants of $R^{2}$ are calculated:

$$
\begin{gathered}
R_{\text {within }}^{2}=\operatorname{corr}^{2}\left(y_{i t}-\bar{y}_{i}, \hat{\beta}\left(x_{i t}-\bar{x}_{i}\right)\right), \\
R_{\text {between }}^{2}=\operatorname{corr}^{2}\left(\bar{y}_{i}, \hat{\beta} \bar{x}_{i}\right), \\
R_{\text {overall }}^{2}=\operatorname{corr}^{2}\left(y_{i t}, \hat{\beta} x_{i t}\right) .
\end{gathered}
$$

All three variants of $R^{2}$ are calculated for each type of model, despite the fact that for a fixed effect model the estimation $\hat{\beta}_{C V}$ is used, a random-effect model implies the estimation $\hat{\beta}_{G L S}$, and for a pooled model $\hat{\beta}_{O L S}$ is applied. The significance of regression models in general is tested using the $F\left(\alpha, v_{1}, v_{2}\right)$ criterion for the model with determined effect; for the models with individual effect $F$-test is replaced by the Wald test (Wald chi2(v)). To test the significance of random effects, the method is applied which was suggested by Breusch and Pagan. It is the Lagrange multiplier method $(L M)$, based on the residuals of the simple OLS-regression. Test of Lagrange multipliers allows to estimate the model under the null hypothesis $\left(H_{0}: \sigma_{u}^{2}=0 ; H_{0}: \sigma_{u}^{2} \neq 0\right)$ and to check whether the gradient of likelihood function is significantly different from zero. For this purpose, the test statistic is used: 


$$
L M=\frac{n T}{2(T-1)} *\left[\frac{\sum_{i=1}^{n}\left[\sum_{t=1}^{T} e_{i t}\right]^{2}}{\sum_{i=1}^{n} \sum_{t=1}^{T} e_{i t}^{2}}-1\right]^{2}=\frac{n T}{2) T-1)} *\left[\frac{\sum_{i=1}^{n}\left(T \vec{e}_{i}\right)^{2}}{\sum_{i=1}^{n} \sum_{t=1}^{T} e_{i t}^{2}}-1\right]^{2},
$$

where $e_{i t}$ - the residuals in standardized regression model.

Under the null hypothesis $L M$ is adhered to the distribution law $\chi^{2}$ (chi-square) with one degree of freedom. High values of the test statistic (low empiric confidence probability, $p$-value) show that the null hypothesis on the possibility to ignore individual effects and to combine the data should be rejected in favour to the random effect model. When considering models with random and fixed effects, it is important to choose the type of model, i.e. to verify the model specification. There is a statistical test of the hypothesis of orthogonality of random effects and regressors. For this purpose, the Hausman test for the correlation of regressors and errors. This approach is based on the fact, that if the hypothesis of no correlation is true, then the estimates of the models with fixed and random effects are consistent, but the estimates of random effects are effective. Therefore, when the null hypothesis is true, there is no systematic bias between the estimates. When the alternative hypothesis is true, only the estimates of a fixed effect model are consistent.

If the alternative hypothesis is true, then the statistic

$$
W=\left[b_{F E}-b_{R E}\right]^{\prime}\left[\operatorname{Cov}\left(b_{F E}\right)-\operatorname{Cov}\left(b_{R E}\right)\right]^{-1}\left[b_{F E}-b_{R E}\right],
$$

asymptotically adheres to the $\chi^{2}$ distribution law with $K$ degrees of freedom, where $\operatorname{Cov}\left(b_{F E}\right)$ and $\operatorname{Cov}\left(b_{R E}\right)$ are the estimates of covariance matrix for the parameters of the models with fixed and random effects. If the observed value of $W$ statistics does not belong to the critical area $W_{\text {наби }}<\chi_{\text {криг }}^{2}$, then the differences between the estimates are not systematical. This means that it is necessary to choose the random effect model. Otherwise, when $W_{\text {набл }}>\chi_{\text {крит }}^{2}$, we should choose a fixed effect model.

\section{Results}

One of the main objectives of state in the development and implementation of socio-economic policy is to coordinate the main trends of the regional development. Successful solution of this task is impossible without taking into account all social and economic factors and consequences. In particular, insufficiently effective labour market leads to social tension and, potentially, to the labour constraints of the number and quality of labour resources, which, in turn, can negate the actions of government aimed at stabilization. In this regard, there is an increasing need to develop adequate tools for the analysis of the labour demand, which allows to describe the relation between the structure of the labour market and the factors, which determine its dynamics.

Characteristic of the current state of employment and labour market in the Mari El Republic and the main factors, which determine market conditions of the demand and supply at the labour market, can be represented in the light of the problems, which exist in the considered field and which are largely inherent for Russia as a whole. At the same time, the regional level has its own specifics.

The desire to maximize the income determines the economic behaviour of any market subject. Income is an ultimate objective of the actions of each active participant of market economy and is a powerful and objective incentive of the daily activities. But the high personal income is beneficial not only for an individual, it is also a socially significant benefit because this income is eventually the only source of addressing the common needs, expansion of production as well as support for low-income and disabled citizens.

Wage in one of the main sources of income, even in a market economy, that is why the processes of labour payment at enterprises and their influence at a state level are always in the spotlight. In the Mari El Republic, in a market economy the problem of payment for labour is one of the most urgent and sensitive. The level of income and primarily the level of wages significantly differ from the all-Russian indicators (Figure 1). 


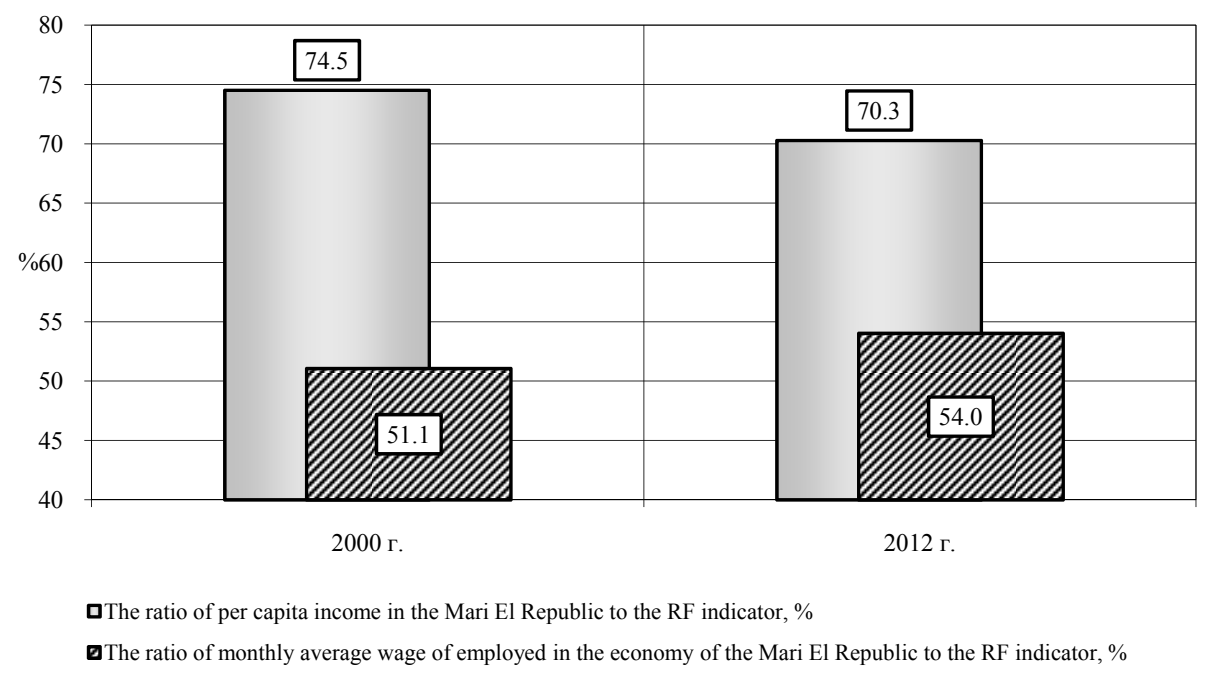

Figure 1. The ratio of the income and wages of the Mari El Republic population to the RF indicators, \%

Comparison of income per capita in the republic and in Russia showed that in 2000 the value of regional indicator was only $51.1 \%$ of the Russian value, and in 2012 the ratio has changed in favour of the regional value, which achieved $54.0 \%$ of the Russian indicator. On the contrary, the study of wages identified significant decrease in wages in the republic against the average wages in Russia: as of 2000, the average wage in the republic was $74.5 \%$ of the Russian average wage, and in 2012 this ratio slightly exceeded $70 \%$. The level of the average wage in the Mari El Republic is significantly different from the average Russian indicator, while the official minimum of subsistence is close to the Russian value (84.5\%). This level of wages stimulates all adult employable members of families to work (sometimes even to combine several jobs), and in the poorest families even teenagers have to work. Underestimated price of the workforce encourages employers to seek additional income, forms a negative attitude toward legalized and fair employment and undermines the credibility of state, which is unable to solve the problem of revenue provision. On the other hand, wage rate depends on employment and the ratio between the labour demand and supply: in a market economy, the labour supply exceeds the labour demand, i.e. workers compete for jobs. There is a trend to reduction of the price of workforce and wages, and the conditions are created for the establishment of wages below the price of labour. The real wage for the last ten years (2002-2012) decreased by more than 16.5 points due to the occurrence and deepening of unjustified wage differentiation.

In the Mari El Republic the ratio of wages by economic activities in 2012 reached 3.4 times. The highest wages in 2012 corresponded to financial activity and amounted to 29298 rubles on average for the republic, and the minimum wage rate was determined for the workers in fishery and fish farming (8742 rubles). Thus, the wage appears as the price of labour, and its size depends on the state of the labour market and primarily on the ratio of the labour demand and supply. The demand for a particular labour is determined by the amount of labour, which entrepreneurs are willing and able to use in the given period of time under the given conditions. In turn, the amount of labour is determined by the number of employed workers, time of their work and labour intensity. The supply of a particular labour is represented by the amount of labour, which the given category of workers is willing and able to provide in the given period of time under the given conditions.

The major role in determining of the wage of certain categories of workers is played by the ratio between the demand and supply of concrete labour. When the supply decreases or the demand increases (for a particular type of labour), the wage of the corresponding workers increases, and vice versa. Study of the ratio between the increase in wages and the increase in the number of enterprises by types of economic activities showed that the maximum value of this indicator corresponds to the sector of hospitality industry, i.e. the number of workers in this type of activity grew much more slowly than their wages, although it does not mean that hotels and restaurants offer the biggest wages. The reason for this outlying case was the reduction in the average staff composition by almost $70 \%$ (Figure 2). 


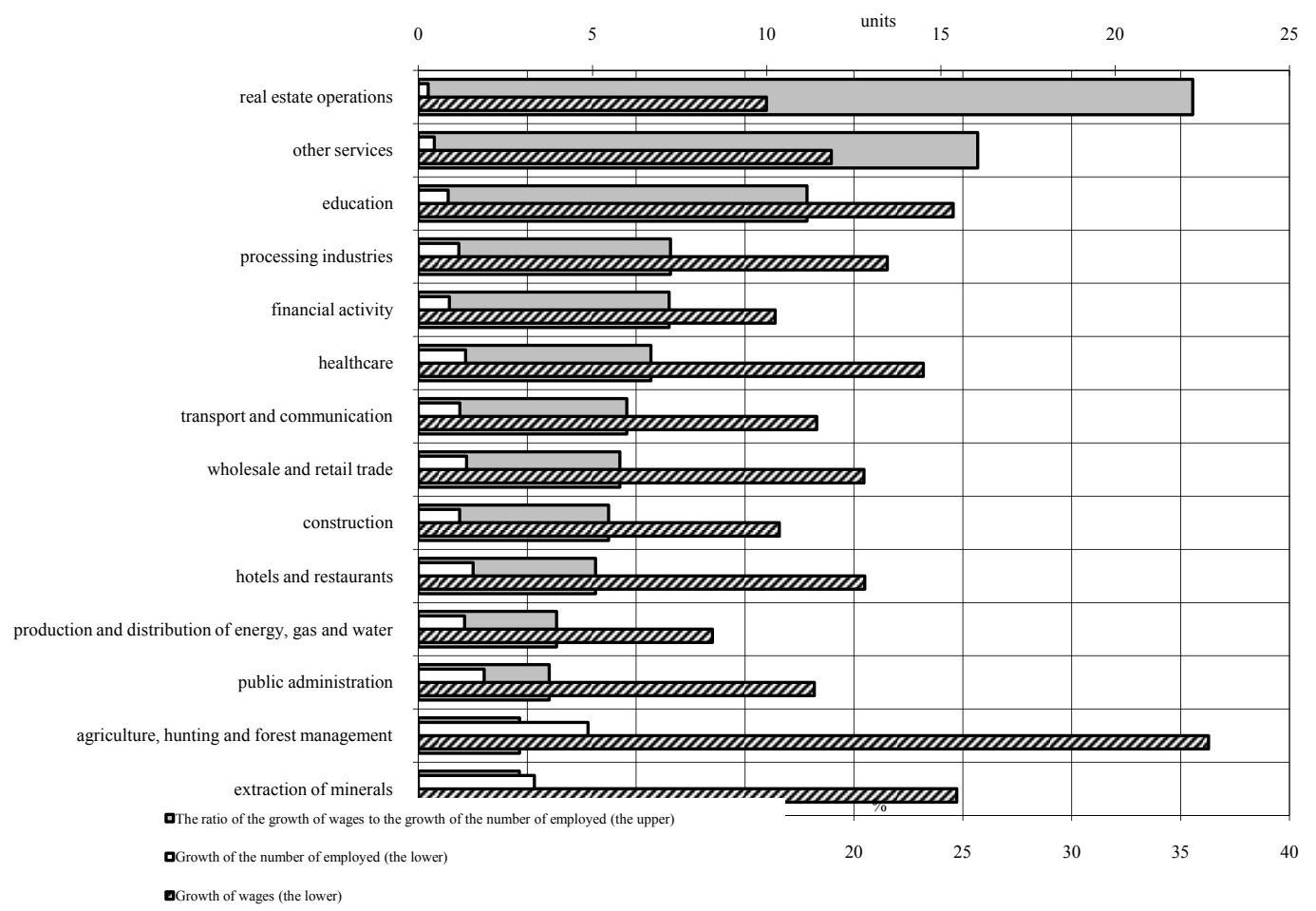

Figure 2. The ratio of the growth of the average wages to the growth of the number of employed by activities for 2000-2012, units

The minimum value of this ratio (43.2) corresponds to real estate operations, for which the wages increased by 9.0 , and the member of employed reduced by $80 \%$. To some extent, this situation can be explained by the fact, that in 2012 the average wage in this sphere in physical terms was only $86.8 \%$ of the average level in the republic. Thus, it was proved that the number of employed in the republic depends on the value of wages, as the latter determines most of the income in the Mari El Republic. Especially strong correlations between the related indicators were identified in construction and public administration, for which the values of coefficients of correlation was 0.65 and 0.86 respectively.

Among other factors, the current economic situation, namely the distribution of enterprises by the economic activities, has a significant impact on employment and the formation of the dynamics of the number of employed. The study of the closeness of correlation between the number of employed and the total number of enterprises as well as the number of public and private enterprises, carried out using correlation analysis, showed strong dependences (Figure 3). 


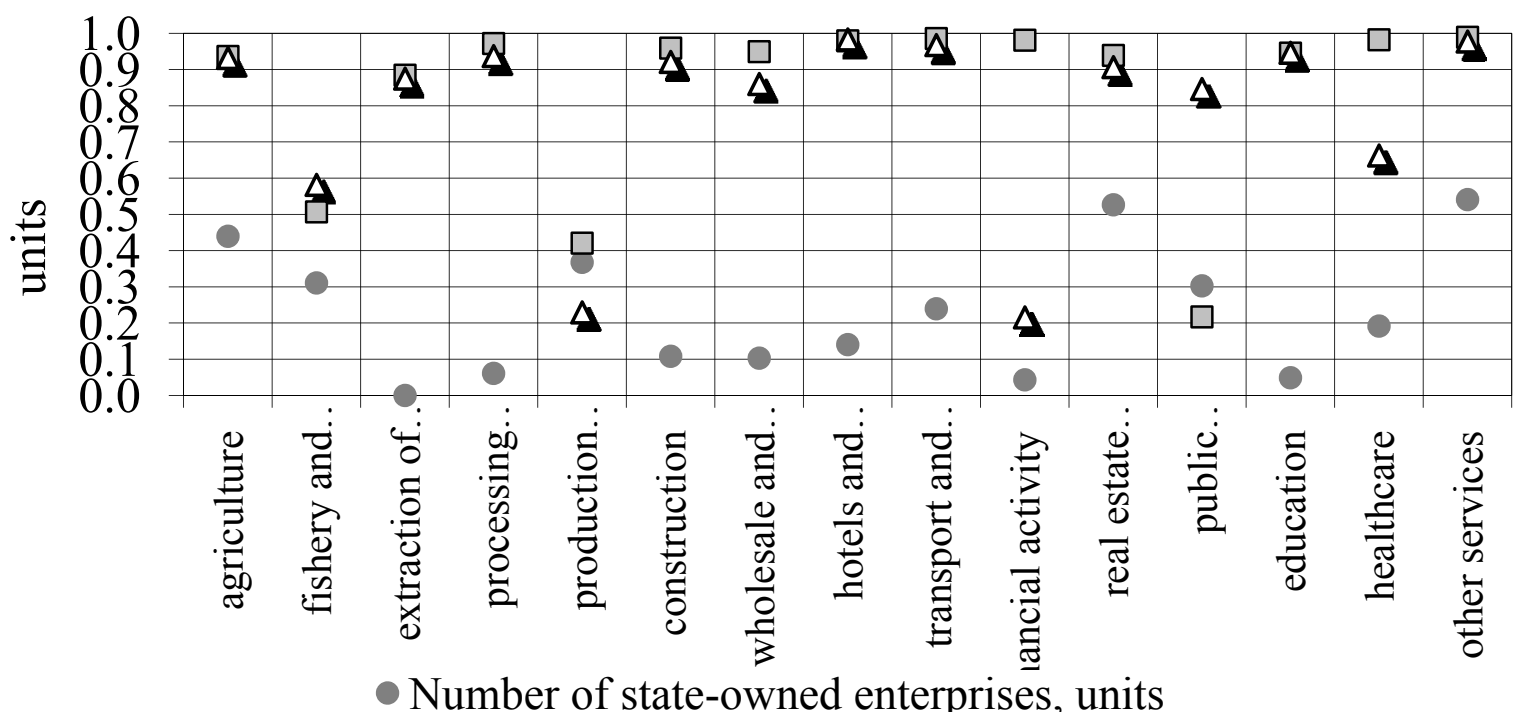

Figure 3. Coefficients of correlation between the number of employed and the number of enterprises by economic activities, units

During the analyzed period, the number of employed had the closest relationship with the number of private enterprises of almost all economic activities excluding financial activity. Financial activity is an activity in which people want to work regardless of the legal form of organization that is caused by high wages in this sphere.

Employment by the types of economic activities is directly related to the indicators of national accounts and national wealth (Fig. 4).

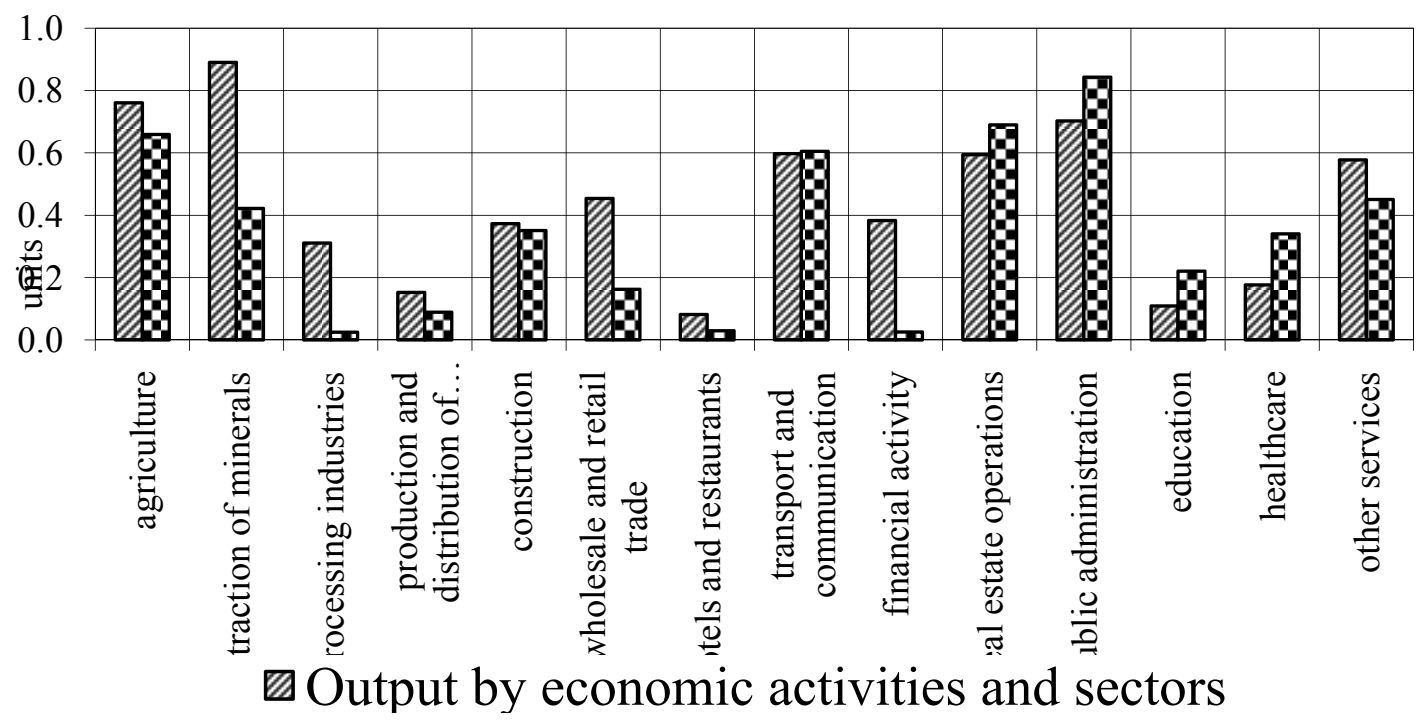

Figure 4. Coefficients of correlation between the number of employed and the indicators of national accounts and national wealth by economic activities, units

Analysis of the coefficients of correlation between the numbers of employed by economic activities and the indicators of national accounts and national wealth, which are shown in the figure, allowed to make a conclusion that production output is an essential factor in industrial spheres of activity: agriculture and processing industries. Fixed assets play an important part in processing industry and agriculture, in this case it is these types of activities, for which the growth rate of the coefficient of fixed assets was significantly above the average value of 
the republic. The average value of fixed assets renewal in agriculture for the last five years was 26.7 , in the sphere of processing industries this value was 14.1. This situtation has led to the fact that the number of employed, especially in agriculture and processing industries, largely depends on the amount of investment in these spheres, and while an increase in investment in agriculture initiates ehe expansion of jobs and provides an increase in employment at the enterprises of this group, for processing industries it leads, on the contrary, to reduction. In the first case, the expansion of production is initiated, and in the other case there is an investment in upgrading of production, as the depreciation of fixed assets is rather high (over $40 \%$ ). In the first case investment projects result in the creation of new jobs and hiring new specialists, and in the second case there is production diversification, changing the qualification of staff and probable decrease in the total number of staff due to technological modernization. The positive dynamics of investment in most activities (construction, transport and communication, healthcare) is connected with large amount of investments in the reconstruction of production facilities as well as in the construction of objects with high degree of construction readiness in order to put into operation the maximum number of social objects.

Using econometric modeling based on a statistical base of socio-economic indictors allows to evaluate and analyze the degree of influence of these indicators on the employment by the types of economic activity. The main modern method of strategic forecasting of complex systems in the world and domestic practice is a model approach.

The method of panel data was applied to construct forecast estimates of the number of employed by types of economic activity at the territory of the Mari El Republic. The data on the number of employed by fifteen main activities $(i)$ for the period from 2006 through $2012(t)$ was used as the values of resultant variable, i.e. the study was conducted for 105 observations:

$y_{i t}$-number of employed in the Mari El Republic in $i$ type of activity, thousand people.

As the factor variables, the following system of indicators for the same time period was used for the construction of model:

1) Income from employment:

$x_{1 i t}$-the average nominal monthly wages of the employees of organizations by economic activities, thousand rubles

2) General characteristics of enterprises:

$x_{2 i t}$-the number of state-owned enterprises and organizations, units;

$x_{3 i t}$-the number of private-owned enterprises and organizations, thousand units;

$x_{4_{i t}}$ - the turnover of organizations by economic activities, bln. rubles;

3) Indicators of national accounts and national wealth:

$x_{s_{i t}}$ - the output by economic activities and sectors, bln. rubles;

$x_{6_{i i t}}$ - the gross value added by economic activities, bln. rubles;

$x_{7_{i t}}$ - the fixed assets by economic activities, bln. rubles

4) Investments in non-financial assets:

$x_{8_{i t}}$ - the investments in fixed capital by economic activities, bln. rubles.

At the first stage of the study a pooled model was build, which contained all time periods (years) and all types of activity. It did not take into account the panel nature of the data. The results are shown in Table 1. 
Table 1. Coefficients of a pooled model and their significance

\begin{tabular}{llll}
\hline Indicators & Coefficients & $t$-statistics & $p$-value \\
\hline const & 12.50 & 6.17 & 0.00 \\
$x_{1_{i t}}$ & -0.85 & -4.60 & 0.00 \\
$x_{2_{i t}}$ & 0.03 & 6.07 & 0.00 \\
$x_{3_{i t}}$ & 3.85 & 3.84 & 0.00 \\
$x_{4_{i t}}$ & 0.41 & 4.09 & 0.00 \\
$x_{5_{i t}}$ & 0.29 & 1.18 & 0.24 \\
$x_{6_{i t}}$ & 1.57 & 2.23 & 0.03 \\
$x_{7_{i t}}$ & 0.16 & 2.64 & 0.01 \\
$x_{8_{i t}}$ & -3.84 & -4.57 & 0.00 \\
\hline
\end{tabular}

Most variables of the build model are statistically significant. Insignificance was determined for the indicator, which characterized the volume of output by economic activities and sectors $\left(x_{s_{i t}}\right)$; after its elimination the pooled model, showing the number of employed by economic activities, looked as follows:

$$
\begin{aligned}
& \hat{y}_{i t}=12.16-0.84 x_{1_{i t}}+0.03 x_{2_{i t}}+3.82 x_{3_{i t}}+0.43 x_{4_{i t}}+2.29 x_{6_{i t}}+0.15 x_{7_{i t}}-3.60 x_{8_{i t}} \\
& (t \text {-statistics }) \quad(-4.57) \quad(6.01) \\
& \text { (2.47) } \quad(-4.41) \\
& R^{2}=0.77 ; \quad F_{\text {набл. }}=45.87 ; \text { S.E. }=9.02
\end{aligned}
$$

The number of employed by economic activities was most influenced by the factor $x_{6_{i t}}$, characterizing the gross value added, and the minimum influence corresponds to the factor $x_{7_{i t}}$-fixed assets by economic activities, bln. rubles. Among the factors, included in the model, only two had a negative effect on the resulting variable. These are $x_{1 i t}$-the average nominal monthly wages of the employees of organizations by economic activities and $x_{8_{i t}}$ -investments in fixed capital by economic activities. This is primarily connected with the fact that the increase in both wages and investments determines the use of innovative technologies, which in turn influence modernization and technologization of production processes. These processes lead in the reduction of manual labour and, consequently, in reduction of jobs. Characteristics of the quality of the model proved its statistical significance and reliability. However, despite the fact that pooled regression model is built based on panel data, it provides inconsistent estimates, because it does not take into account individual heterogeneity.

Further study was conducted based on regression analysis of panel data, which included three dimensions - variables, objects and time. In order to use panel data and the corresponding benefits of analysis, it was important to verify the possibility to create a single panel; therefore for each year from 2006 to 2012 regressions were built as follows:

$$
y_{i}=b_{0}+b_{1} x_{1 i}+b_{2} x_{2 i}+b_{3} x_{3 i}+b_{4} x_{4 i}+b_{5} x_{5 i}+b_{6} x_{6 i}+b_{7} x_{7 i}+b_{8} x_{8 i}
$$

Coefficients in the models should be of the same order. The obtained coefficients are shown in Table 2. 
Table 2. Regression coefficients in time section

\begin{tabular}{llllllllll}
\hline $\mathrm{t}$ & $b_{0}$ & $b_{1}$ & $b_{2}$ & $b_{3}$ & $b_{4}$ & $b_{5}$ & $b_{6}$ & $b_{7}$ & $b_{8}$ \\
\hline 2006 & 4.24 & -0.11 & 0.04 & 11.93 & -0.70 & 4.26 & -4.37 & 0.11 & -6.99 \\
2007 & 5.11 & 0.50 & 0.03 & 16.75 & -1.07 & 4.37 & -6.63 & 0.09 & -7.56 \\
2008 & 5.79 & -0.26 & 0.03 & 5.54 & -0.51 & 1.87 & 1.06 & 0.10 & -4.65 \\
2009 & 12.99 & -1.10 & 0.05 & 4.23 & 0.79 & 1.05 & -0.04 & 0.29 & -7.00 \\
2010 & 10.30 & -0.95 & 0.04 & 4.09 & 0.66 & 0.41 & 1.41 & 0.21 & -5.99 \\
2011 & 8.61 & -0.65 & 0.04 & 2.00 & 0.36 & -0.52 & 3.96 & 0.31 & -6.67 \\
2012 & 9.89 & -0.66 & 0.03 & 2.70 & 0.24 & -0.57 & 3.63 & 0.21 & -4.16 \\
\hline
\end{tabular}

Analysis of the coefficients showed that the necessary condition for the possibility to create a panel is met, and data aggregation and its study as a single panel are justified.

In order to identify the main factors and to evaluate their influence on the number of employed in terms of the types of economic activity, different regression models were built based on panel data. The best result of approximation was achieved using the model with random individual effects. Lagrange multipliers test allowed to identify the benefit of random effect model, as the value $L M=14,03$ is statistically significant. Individual heterogeneity in model was taken into account not in the equation, but in the the covariation matrix, which was block-diagonal, since random effects correlate between each other within each. Generalized least squares method was used to estimate the regression coefficients.

Elimination of the factor $x_{s_{i t}}$, which was insignificant in compliance with the $z$ criterion, allowed to simplify the model, in which seven independent variables remained as in the case of pooled regression:

$$
\begin{gathered}
\hat{y}_{i t}=9.98-0.58 x_{1_{i t}}+0.01 x_{2_{i t}}+1.88 x_{3_{i t}}+0.35 x_{4_{i t}}+0.65 x_{6_{i t}}+0.05 x_{7_{i t}}-0.80 x_{8_{i t}} \\
(z-\text {-statistics }) \\
(-4.91)
\end{gathered}
$$

Regression coefficients $R_{\text {between }}^{2}=0.81$ and $R^{2}$ within $=0.70$ are high, reflecting the quality of the fitting.

As the difference between the coefficients is small, within the model interindividual differences of the features appear no more than dynamic differences. Consequently, the change in time average indicators for each type of economic activity has a significant impact on each variable, as well as the temporal variations of these factors with regard to the averages. The significance of the regression equation is generally determined by high value of the Wald statistic Wald chi $2=42.68$ and the significance level of $\mathrm{p}=0.0000$, which does not exceed 0.05 . The regressors are uncorrelated with unobserved random effects, which is evidenced by the value $\operatorname{corr}\left(u_{-} i, X\right)=0$ (assumed). The model coefficients are statistically significant, since $p<0.05$ for all parameters of the equation.

When interpreting the impact of the employment indicators by all types of activities in general, we can conclude that the increase of the number of employed is positively influenced by both private and state owned enterprises. The more the number of enterprises of any form of ownership is, the higher the employment is in any type of economic activity. The growth of nominal wages leads to the reduction of employment. This fact can not serve as a proof that people want to work for a small wage; it only confirms the existence of disparities in the structure of employment by economic activities. The problem of matching the wage rate and the labour price can be solved by the flexible regulation of wages taking into account the enterprise results and the personal labour contribution of each worker. The feasibility of such approach can be explained by the fact, that the achievement of higher production efficiency by updating the product range, improving product quality, reducing the costs, etc., increases the demand for the products and consequently for workers who produce such goods. At the same time, by linking wages with the enterprise results, a prompt response to changing supply and demand at the labour 
market can be provided.

\section{Discussion}

Modern economics has enough tools, among them a special place belongs to the methods of statistical analysis and forecasting, which does not depend on subjective perceptions and preferences. It is statistical methods and econometric models, which can help to understand the current situation in the sphere of employment and to choose adequate tools for its regulation.

An important part in the study of general theoretical and methodological issues of employment is played by Russian and foreign scientists in the field of economic analysis and statistics: T. I. Bezdenezhnykh, B. D. Breev, Y. G. Volgin, T. B. gauzner, A. E. Kotlyar, V. V. Mayer, S. G. Mikhneva, V. I. Plaksya, E. R. Sarukhanov, ПБУб Slezinger, D. Y. Stiglits and others. Development of the methodology of statistical study of employment was carried out by such Russian scientists as I. I. Eliseeva, Y. M. Zabrodin, N. V. Zubarevich, M. V. Karmanov, A. G. Korovkin, V. I. Kuznetsov, O. V. Kuchmaeva, A. Y. Oshchepkov, N. M. Rimashevsky and others. A sufficient number of works of T. N. Agapova, S. A. Ayvazyan, V. N. Afanasiev, V. A. Balash, V. P. Bozhko, I. K. Belyaevskiy, M. Veber, T. A. Dubrova, M. D. Kendell, A. V. Korotkov, Y. P. Lukashin, V. G. Minashkin, V. S. Mkhitaryan, B. T. Ryabushkin, Y. V. Sazhin, A. A. Frenkel are devoted to statistical analysis and forecasting.

At the same time, many issues, connected with the improvement of analysis and forecasting of the development of the sphere of regional employment, study of its main features in term of time and space, especially at the stages of economic crisis and recovery, require the application of the new methodological approaches, as the methodologies and models of statistical analysis and forecasting of the prospects of the development of employment, which are worked out for Russia as a whole, have specific nature and are not quite suitable for individual small regions and municipalities. The main reason for this is the heterogeneity of the processes which take place in certain regions of the country, where the unstable economic situation leads to the increase in variation of statistical values.

\section{Conclusions}

At the present stage, in the Mari El Republic we can identify the number of key problems of matching the labour demand and supply in the sphere of employment and the labour market.

In terms of the demand for labour, the problems are: heterogeneity of the labour demand in the economic sectors significant differentiation in the level of wages in economic sectors; low level of labour productivity in the number of economic sectors, which is determined by the corresponding capital intensity and labour organization.

In terms of the supply of labour, the problems are: heterogeneity of the labour supply in sectors due to different job attractiveness concerning career perspectives and the reduction of the number of employed in a number of industries, which are priorities in terms of the development of innovative economy, especially in a real sector.

At the same time, there is the "poverty" of the labour potential. Quality (structural) mismatch of the labour demand and supply leads to structural unemployment and unsatisfied demand for labour: ineffective use of workforce, as most people do not work within their specialty and work with the loss of income level. Current needs of economic development determine high demand for "non-innovation personnel". This prevents solving the fundamental problem of training staff for innovative economy, creation of which, therefore, requires resource costs, which are primarily taken from the internal reserves.

\section{Acknowledgment}

This article was prepared under a grant of the Russian Humanitarian Science Foundation (project "Demoekonomichesky potential of the region: macrosystemic approach" \# 15-02-00567).

\section{References}

Am, J. (2011). Random-Effects Model Aimed at Discovering Associations in Meta-Analysis of Genome-wide Association Studies. Hum Genet, 88(5), 586-598. http://dx.doi.org/10.1016/j.ajhg.2011.04.014

Anselin, L. (1999). Spatial Econometrics. Retrieved from http://www.csiss.org/learning_resources/content/ papers/baltchap.pdf

Arellano, M. (1993). On the testing of correlated effects with panel data. Journal of Econometrics, 59, 87-97. http://dx.doi.org/10.1016/0304-4076(93)90040-C

Bai, J. (2013). Fixed-Effects Dynamic Panel Models, a Factor Analytical Method. Econometrica, 81(1), 285-314. http://dx.doi.org/10.3982/ECTA9409

Breusch, T. S., Mizon, G. E., \& Schmidt, P. (1989). Efficient estimation using panel data. Econometrica, 57, 
695-700. http://dx.doi.org/10.2307/1911060

Breusch, T. S., \& Pagan, A. R. (1980). The Lagrange multiplier test and its applications to model specification in econometrics. Review of Economic Studies, 47, 239-253. http://dx.doi.org/10.2307/2297111

Hardy, R. J., \& Thompson, S. G. (1996). A likelihood approach to meta-analysis with random effects. Stat. Med., 15, 619-629. http://dx.doi.org/10.1002/(SICI)1097-0258(19960330)15:6<619::AID-SIM188>3.0.CO;2-A

Hausman, J. B., Hall, B., \& Griliches, Z. (1984). Econometric Models for Count Data with an Application to the Patents-R \& D Relationship. Econometrica, 52(1), 909-938. http://dx.doi.org/10.2307/1911191

Lipsitz, S. R. (1992). Methods for estimating the parameters of a linear model for ordered categorical data. Biometrics, 48(1), 271-281. http://dx.doi.org/10.2307/2532755

Gibbons, R. D., \& Hedeker, D. (1997). Random effects probit and logistic regression models for three-level data. Biometrics, 53, 1527-1537. http://dx.doi.org/10.2307/2533520

\section{Copyrights}

Copyright for this article is retained by the author(s), with first publication rights granted to the journal.

This is an open-access article distributed under the terms and conditions of the Creative Commons Attribution license (http://creativecommons.org/licenses/by/3.0/). 